\title{
BENEFÍCIOS AMBIENTAIS DA ENERGIA FOTOVOLTAICA
}

\section{ENVIRONMENTAL BENEFITS OF PHOTOVOLTAIC ENERGY}

Alexandre Betassa de Souza - alexandre.betassa.souza@hotmail.com

André Luiz Oliveira - andre.adv@uol.com.br Faculdade de Tecnologia de Taquaritinga (FATEC) -SP -Brasil

DOI: 10.31510/infa.v16i2.644

\section{RESUMO}

A necessidade de diversificação da matriz energética brasileira é tema recorrente nos diversos painéis que discutem a questão ambiental, quando a pauta é geração de energia. Não é de hoje que o país convive com a ameaça de "apagões" em virtude de alterações nos regimes de chuva, que afetam diretamente a capacidade de geração de energia das usinas hidroelétricas, responsáveis por $61 \%$ da geração de energia no país. Este trabalho evidenciou a necessidade e os benefícios da utilização de matrizes energéticas limpas, com ênfase para a energia produzida a partir da captação dos raios solares, denominada fotovoltaica, que possui diversos benefícios especialmente benefícios ambientais) em comparação com outras fontes de energia. Foram destacadas as potencialidades ambientais e econômicas desse processo, ilustradas por um estudo de caso apresentado ao final do trabalho.

Palavras-chave: Energia Fotovoltaica. Sustentabilidade. Gestão Ambiental. Economia.

\begin{abstract}
The need for energy matrices diversification is a recurring theme in the various panels that discuss the environmental issue, when the topic is power generation. It is not from today that the country lives with the threat of "Blackouts" due to changes in rainfall regimes, that affects directly the capacity of power generation of hydroelectric plants, responsable for $61 \%$ of power generation in the country. This work has highlighted the need and benefits of using clean energy matrices, with emphasis on energy produced from the capture of the sun's rays, called photovoltaic, which has several benefits especially environmental benefits compared to other energy sources. The environmental and economic potentialities of this process were highlighted, illustrated by a case study presented at the end of this work.
\end{abstract}

Keywords: Photovoltaics. Sustainability. Environmental management. Economy.

\section{INTRODUÇÃO}

A preocupação com a preservação do meio ambiente, temática crescente nos dias atuais, gera a necessidade de busca da diversificação da matriz elétrica, quadro agravado pelo aumento na demanda por energia e desenvolvimento do setor industrial, cenário que leva à necessidade de se repensar a utilização de fontes renováveis de energia, como a fonte solar. 
De acordo com Nascimento (2017), muito embora sejam consideradas fontes que demandam investimento inicial relativamente elevado, se tornam extremamente competitivas à medida em que ocorre o fenômeno de sua expansão, em virtude de redução de custos oriunda de ganho de escala e dos incessantes avanços tecnológicos no setor.

O Brasil, por suas características naturais, possui considerável e expressivo potencial para geração de energia elétrica a partir de fonte solar, uma vez que o país conta com níveis de irradiação solar superiores aos de países onde projetos para aproveitamento de energia solar são amplamente disseminados, como Alemanha, França e Espanha. Prossegue o autor, afirmando:

\footnotetext{
Apesar dos altos níveis de irradiação solar no território brasileiro, o uso da fonte para geração de energia elétrica não apresenta a mesma relevância que possui em outros países, nem o mesmo desenvolvimento de outras fontes renováveis, como eólica e biomassa, que já representam, respectivamente, $6,7 \%$ e $9,4 \%$ da capacidade de geração instalada no Brasil, contra apenas $0,05 \%$ da fonte solar (NASCIMENTO, 2017, p. 04).
}

De acordo com Reis (2019), A energia elétrica foi descoberta pelo filosofo grego Thales de Mileto (600 a.C.) quando, ao esfregar um pedação de âmbar na pele de um carneiro, reparou que fragmentos de determinados materiais começaram a ser atraídos. Desde então seus estudos e avanços foram gigantescos, sendo certo que a sociedade moderna, como a conhecemos, seria inimaginável sem energia elétrica.

É através da energia elétrica que as atividades mais simples e corriqueiras do dia a dia podem se desenvolver regularmente, como acender a luz em casa ou no trabalho, carregar os aparelhos smartphones, movimentar máquinas e motores nas empresa, manter aparelhos em hospitais, enfim, a energia elétrica se tornou um produto de indescritível importância para a sobrevivência humana, no sentido de atender as suas necessidades.

\section{FUNDAMENTAÇÃO TEÓRICA}

As seções a seguir apresentam os principais conceitos teóricos envolvidos no contexto deste trabalho.

\subsection{O Consumo De Energia Elétrica No Brasil}

De acordo com a ANEEL (2008), o consumo de energia reflete o desenvolvimento de qualquer sociedade, mas o seu consumo elevado (cenário atual no Brasil), embora evidencie 
um ponto positivo (aquecimento da economia), traz consigo pontos negativos, como altos custos para descobertas de novas e mais eficientes tecnologias para a geração de energia elétrica, bem como a construção dessas fontes geradoras. Portanto, segundo o órgão oficial, o método mais utilizado não somente no Brasil mas em outros países, tem como foco o consumo de energia com mais eficiência. No Brasil, por exemplo, foi criado o PROCEL (Programa Nacional de Conservação de Energia Elétrica) que visa incentivar o consumo mais eficiente dessa energia, a fim de conter e controlar a expansão da geração.

Segundo dados do Ministério de Minas e Energia no Brasil (MME, 2002), as características físicas e geográficas do Brasil contribuíram para que até agora a principal fonte geradora de energia no Brasil fosse a geração hidroelétrica, que corresponde a $90 \%$ da energia gerada e consumida internamente. Embora o sistema de geração hidroelétrico brasileiro demonstre grande potencial, o aumento exponencial do consumo de energia elétrica nas residências, indústrias e comércios faz com que esse sistema não acompanhe o aumento, forçando o país a utilizar outras fontes geradoras renováveis e não renováveis. Como consequência deste cenário, a discussão a respeito da necessidade de racionamento da energia elétrica é tema recorrente, em especial nos momentos em que o país se depara com falta de energia em decorrência do regime das chuvas.

\subsection{Fontes De Energia Renováveis E Não Renováveis}

De acordo com a Empresa de Pesquisa de Energética (EPE), fontes de energia não renováveis (conhecidas também como fontes de energia convencionais) correspondem a matrizes energéticas que podem vir a se esgotar futuramente, pois normalmente essas fontes são retiradas do meio natural, onde levaram milhares de anos para serem produzidas. Ainda de acordo com o órgão, trata-se de uma fonte considerada a mais utilizada no mundo, muito embora sejam as mais poluentes, pois para seu processamento é necessário o processo de “queima", gerando impactos ambientais sérios, dentre eles, a emissão de gases de efeito estufa.

Ainda de acordo com a EPE, as fontes de energia renováveis são matrizes energéticas inesgotáveis, pois se renovam continuamente, como por exemplo a energia solar, eólica, proveniente da biomassa, dentre outras. Por esta razão são consideradas matrizes energéticas "limpas" em relação às fontes não renováveis, muito embora a energia hidroelétrica não seja considerada totalmente limpa, uma vez que também gera danos ambientais, como a queima de 
combustíveis e impactos ambientais diretos sobre a flora e a fauna do local onde estão instaladas.

\subsection{Energia Fotovoltaica}

De acordo com o site Portal Solar (2016), o efeito fotovoltaico (princípio da geração de energia fotovoltaica), foi descoberto pelo físico francês Alexandre Edmond Becquerel no ano de 1839, quando realizava experiencias com eletrodos. No entanto, já naquela época ainda era vista com uma tecnologia para o futuro e devido aos seus altos custos ainda era utilizado apenas por cientistas, havendo muito ceticismo com relação à possibilidade de que esta matriz energética pudesse um dia ser disponibilizada para a sociedade.

No entanto, com pesquisas científicas desenvolvidas sobre o tema, além da evolução da tecnologia, este cenário se alterou quando Albert Einstein (que recebeu em 1923 o Prêmio Nobel pela descoberta da lei do Efeito Fotoelétrico) e o químico americano Call Fuller (que criou um processo de dopagem do silício, potencializando os efeitos da geração fotovoltaica com utilização de boro e o arsênio), apresentaram formalmente a primeira célula fotovoltaica em 25 de Abril de 1954 em uma reunião anual National Academy of Sciences, realizada na cidade de Washington, EUA.

Nascimento (2017) realizou um estudo técnico para a Câmara dos Deputados visando observar os incentivos na legislação, além de propor discussões para transpassar obstáculos visando aumentar a potência de energia fotovoltaica na matriz energética brasileira. Seus estudos concluíram que a energia elétrica é produzida diretamente através das células solares, que transforma a luz solar em energia elétrica através dos fótons, efeito fotoelétrico descoberto em 1839 pelo físico francês Edmond Becquerel, e dentre os materiais mais adequados para a construção das células solares, o silício cristalino, é o que está presente em $80 \%$ das células fotovoltaicas.

\section{PROCEDIMENTOS METODOLÓGICOS}

A presente pesquisa possui caráter descritivo e exploratório e procura evidenciar uma questão totalmente voltada para um dos principais desafios da agenda ambiental e energética 
brasileira: a necessidade de adoção de matrizes energéticas limpas e sustentáveis, reduzindo a dependência do país com relação às usinas hidroelétricas e do "cada vez mais" inconstante regime de chuvas.

Para tanto, foi traçado um panorama geral a respeito dos benefícios oriundos da utilização da energia solar através de sua captação por placas fotovoltaicas, como alternativa à matriz energética dominante atual, como forma de mitigar os danos ambientais oriundos da energia gerada pela força das águas.

De acordo com Gil (2006), o objetivo de uma pesquisa exploratória é compreender um assunto ainda pouco estudado. $\mathrm{O}$ estudo de caso, dentro de uma pesquisa exploratória, referese a uma situação, entidade ou conjunto de entidades que têm um mesmo comportamento ou são do mesmo perfil.

O estudo de caso apresentado ao final como forma de ilustrar o conteúdo teórico, demonstra a viabilidade de se agregar valor ambiental no processo de geração de energia de forma limpa e sustentável, gerando benefícios não somente de ordem financeira, mas social.

\section{RESULTADOS E DISCUSSÃO}

De acordo com a ANEEL (2019), no Brasil são usada diversas matrizes energéticas, dentre as quais é possível citar a biomassa, a geração de energia através do vento (eólica), a queima de combustíveis fosseis, energia nuclear, fotovoltaica, dentre outras. Ainda segundo o órgão oficial, a principal origem da energia elétrica brasileira é oriunda dos recursos hídricos que o território possui, as chamadas usinas hidroelétricas, responsáveis por cerca de $60,81 \%$ da energia utilizada em todo território nacional, geração propiciada por aproximadamente 1352 usinas construídas.

Segundo LEMKE (2018), embora seja considerada uma fonte renovável de energia, este modelo traz consigo impactos ambientais consideráveis, como por exemplo a existência de grandes áreas alagadas, que provocam drástica modificação na paisagem, gerando impacto ambiental visual de grande espectro, afetando ainda a fauna e flora locais, destruindo habitats de animais residentes, inclusive com mortandade de espécies (em especial filhotes que não encontram meios para fuga do local), em virtude do represamento da área que torna a vegetação submersa. Com a decomposição das carcaças desses animais, ocorre liberação de gases de efeito estufa na atmosfera. 
De acordo com o Ministério de Minas e Energia no Brasil (MME, 2002), as características físicas e geográficas do Brasil contribuíram para que até agora a principal fonte geradora de energia no Brasil fosse a geração hidroelétrica, que corresponde a $90 \%$ da energia gerada e consumida internamente. Embora o sistema de geração hidroelétrico brasileiro demonstre grande potencial, o aumento exponencial do consumo de energia elétrica nas residências, indústrias e comércios faz com que esse sistema de geração de energia não acompanhe essa demanda na mesma proporção, forçando o país a utilizar outras fontes geradoras renováveis e não renováveis.

Para Nascimento (2017), devido ao grande crescimento da demanda de energia elétrica aliada à preocupação ambiental, busca-se fontes alternativas de geração de energia elétrica. Em outras palavras, segundo o autor, fontes limpas que não agridam o meio ambiente e que sejam renováveis. Prossegue o autor afirmando que essa busca foi intensificada depois que o Brasil assinou um tratado na Convenção das Partes (COP 21 - Cúpula do clima), realizada em Paris na França, em que se comprometia reduzir a emissão de gases do efeito estufa entre $37 \%$ a $43 \%$ até 2025 e 2030 respectivamente, se comparado com os níveis de 2005.

Ante este cenário, a energia fotovoltaica surge com uma ideia atrativa, uma vez que há grande incidência de raios solares no Brasil, embora o país seja um dos que menos utiliza essa tecnologia. Segundo o autor, de acordo com estudos realizados no ano de 2017, a participação da tecnologia na matriz energética brasileira foi de apenas $0,05 \%$, valor muito aquém do que o praticado em países que já possuem essa tecnologia amplamente disseminada, como é o caso como a Espanha e Alemanha.

\footnotetext{
“As fontes renováveis, embora inicialmente mais caras, tornam-se mais competitivas na medida em que se expandem, sendo a competitividade resultante da redução dos custos devido ao ganho de escala e dos avanços tecnológicos "(NASCIMENTO, 2017, p. 04).
}

De acordo com Ricardo Rüther (2004), o Brasil possui enorme potencial energético através do sol. O autor valida seu posicionamento citando o caso da Usina de Itaipu que contribui com $25 \%$ da energia elétrica consumida no país. A título de projeção, conclui que, se fosse possível cobrir o lago de Itaipu com células solares, haveria a obtenção de $50 \%$ da energia elétrica consumida no Brasil, ou seja, com o espaço de uma usina de Itaipu que contribui com $1 / 4$ da energia consumida no país, haveria uma dobra de eficiência energética com a utilização do sistema fotovoltaico. 
Diariamente incide sobre a superfície da terra mais energia vinda do sol do que a demanda total de todos os habitantes de nosso planeta em todo um ano. Dentre as diversas aplicações da energia solar, a geração direta de eletricidade através do efeito fotovoltaico se apresenta como uma das mais significativas formas de gerar potência elétrica (RÜTHER, 2004, p. 08).

As principais vantagens da energia solar são:

- Durante a geração, a energia fotovoltaica não emite poluente ou sons;

- Seus custos com manutenção são mínimos e a instalação pode ocorrer em área remotas;

- A tecnologia vem sendo melhorada, e com isso os equipamentos se tornam melhores e seus custos tendem a reduzir;

- No Brasil, o sistema fotovoltaico se apresenta como uma grande alternativa por conta do elevado índice de raios solares (PEDRO REIS, 2017, p. 30)

O mesmo autor elenca, como fragilidades dessa matriz energética, a variação na quantidade de geração durante as intempéries e estações do ano e a necessidade de se aumentar a eficiência dos painéis energéticos, atualmente estimada em $25 \%$.

Reforçando o estudo realizado por Pedro Reis (2017), o site do programa América do Sol, criado pelo Instituto Ideal, entidade que tem por objetivo a pesquisa de fontes de energia alternativas, cita as vantagens do sistema fotovoltaico instalado em edificações urbanas:

- Redução nas perdas de energia, pois grande parte da geração das residências já é consumida instantaneamente, e somente o excedente é liberado à concessionária, evitando assim as perdas de energia devido à distância percorrida por linhas de transmissão e distribuição, resultando também na redução dos investimentos em novas linhas de transmissão e distribuição.

- Baixo impacto ambiental, pois muitos sistemas podem ser instalados nos telhados das residências e indústrias, não havendo a necessidade de novas áreas físicas e agilidade nos processos de instalação dos geradores fotovoltaicos.

O infográfico apresentado na figura 1 retrata o potencial da matriz energética com utilização dos raios solares em outros países, sendo que China, Índia, Estados Unidos, Japão e Austrália lideram o cenário mundial. Nota-se ainda, que no Brasil, os Estados de Minas Gerais, Rio Grande do Sul e São Paulo foram os que mais investiram nessa modalidade de geração de energia. Em termos gerais, a matriz energética brasileira é essencialmente hidroelétrica (61\%), ao passo que a fotovoltaica corresponde a apenas $1,2 \%$. 


\section{INTERFACETTECNOLÓGICA}

Figura 1: Infográfico Energia Fotovoltaica

\section{O Mercado Fotovoltaico no Mundo}
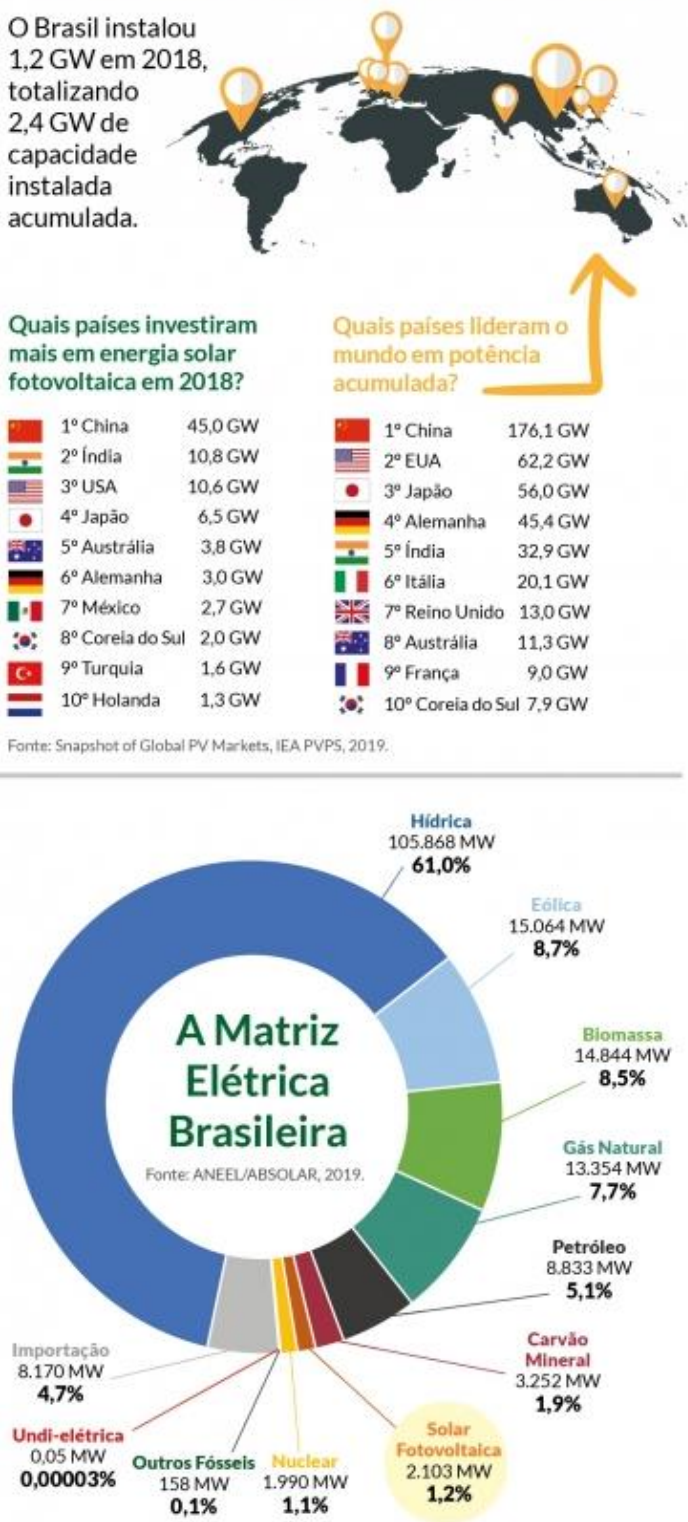

\section{Geração Distribuída \\ Ranking Estadual}



Ranking Municipal Fonte-ANEFIABSOLAR, 2019 Potência Instalada (MW) (\%)

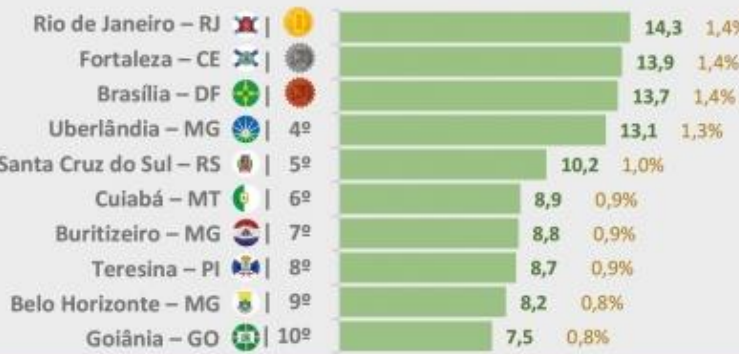

Qual a Potência Instalada Solar Fotovoltaica no Brasil?

$$
\text { Geração Centralizada }
$$
2.103,2 MW

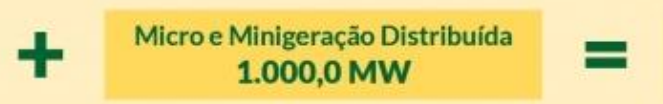

Fonte: ABSOLAR (2019)

Casos práticos que demonstram o potencial da geração de energia pelo sistema fotovoltaico

Com o objetivo de tornar menos abstrato ao leitor as potencialidades da geração de energia pela matriz solar (fotovoltaica), este trabalho identificou uma situação que possibilita identificar de forma mais clara e objetiva os benefícios desse sistema de geração de energia. 
4.1 Estudo de caso realizado junto à empresa PRONTO SOLAR, sediada na cidade de Matão-SP.

Figura 2 - Pré-estimativa técnica comercial

1 - Demanda Energética

O dimensionamento do sistema fotovoltaico foi calculado e elaborado a partir da média de consumo do cliente, descontando a taxa de disponibilidade de acordo com a classificação do padrão de entrada. Dessa forma será possivel produzir o máximo de energia elétrica.

\begin{tabular}{|l|r|l|}
\hline Consumo Mensal Médio & $\mathbf{5 6 0}$ & $\mathrm{KWh}$ \\
\hline Valor Consumo Mensal Médio & $\mathbf{R} \$ 448,27$ & Mês \\
\hline Geração Mensal Estimada & $\mathbf{5 1 0}$ & $\mathrm{KWh}$ \\
\hline Valor Compensação Mensal Estimada & $\mathbf{R} \$ 408,27$ & Mês \\
\hline Média Percentual Compensação & 91,08 & $\%$ \\
\hline Taxa Disponibilidade (220V Bifásico) & $\mathbf{5 0}$ & $\mathrm{kWh}$ \\
\hline Geração Diária Média Estimada & 17,01 & $\mathrm{kWh}$ \\
\hline Valor Mínimo Conta (Após Instalação) + Impostos & $\mathbf{R} \$ 40,00$ & Mês \\
\hline
\end{tabular}

Obs: Por depender diretamente da radiação solar, o cálculo é feito pela média anual da localidade, havendo variação de um mês para outro.

2 - Dimensionamento do Sistema

Sistema fotovoltaico proposto para atender a demanda:

\begin{tabular}{|l|r|l|}
\hline Potência Gerador Fotovoltaico & $\mathbf{4 , 0 2}$ & $\mathrm{kWp}$ \\
\hline Área de Telhado Cerâmico & $\mathbf{2 4 , 2}$ & $\mathrm{m}^{2}$ \\
\hline
\end{tabular}

Peso aproximado por m2 $12 \mathrm{Kg}$.

3 - Equipamentos Principais

\begin{tabular}{|l|r|r|}
\hline Inversor WEG SIW300H M030 & $4050 \mathrm{~W}$ & 1 \\
\hline Módulos Solares GCL 365Wp & $365 \mathrm{Wp}$ & 11 \\
\hline Monitoramento WEB & Interno & 1 \\
\hline
\end{tabular}

Fonte: PRONTO SOLAR (2019)

No caso apresentado, o cliente possui um consumo médio mensal de 560kWh por mês, resultando em uma conta média de energia de $\mathrm{R} \$ 448,27$ (quatrocentos e quarenta e oito reais e vinte e sete centavos) mensais.

Com base nesses dados, é possível afirmar que para suprir a sua demanda, necessita de um sistema de $4,02 \mathrm{kWp}$ para a geração de $510 \mathrm{kWh}$ por mês e uma geração diária média de 17,01Kwh, resultando em uma compensação de $91,08 \%$ da sua conta de energia, provocando uma redução na mesma ao valor mínimo (incluindo impostos), ou seja, $\mathrm{R} \$ 40,00$ (quarenta reais) mensais. Verifica-se, portanto, uma compensação de $\mathrm{R} \$ 408,27$ (quatrocentos e oito reais e vinte e sete centavos) por mês, necessitando somente de uma área de $24,2 \mathrm{~m}^{2}$ para acomodação dos módulos. 
A figura 3 evidencia os investimentos necessários para o projeto, estimados em 20.247,63 (vinte mil, duzentos e quarenta e sete reais e sessenta e três centavos), conforme apresentado na sequência:

Figura 3 - Valor do sistema fotovoltaico $4,02 \mathrm{kWp}$

5 - Valores e Forma Pagamento
\begin{tabular}{|l|r|}
\hline Equipamentos (A vista) - Faturamento Direto WEG & R\$ $11.150,00$ \\
\hline Serviços: Projeto, Insumos Elétricos e Instalação & R\$ $9.723,85$ \\
\hline Desconto Serviços (Pagamento Antecipado) & R\$ 626,22 \\
\hline Valor Total Final (A vista) & R\$ $20.247,63$ \\
\hline
\end{tabular}

Fonte: Pronto Solar (2019)

Este investimento, após todo o equipamento instalado e em plena operação, trará logo o primeiro ano de funcionamento um retorno ao cliente no importe de $\mathrm{R} \$ 4.082,45$ (quatro mil e oitenta e dois reais e quarenta e cinco centavos).

Analisando os dados fornecidos pela empresa e fazendo uma projeção para um prazo de 26 anos (já consideradas algumas variáveis, tais como queda de rendimento do próprio equipamento por conta de sujeiras, vida útil, dentre outros fatores), chega-se à conclusão que o retorno será no valor de $\mathrm{R} \$ 383.548,19$ (Trezentos e oitenta e três mil, quinhentos e quarenta e oito reais e dezenove centavos).

\section{CONCLUSÕES}

Este estudo evidenciou os benefícios da utilização da energia fotovoltaica como uma matriz energética limpa, renovável e de grande potencial no sentido de colaborar com os ideais na busca pelo desenvolvimento sustentável. Restou demonstrado que, quanto maiores os investimentos em estudos que possam potencializar a eficiência dessa matriz energética, maior será a sua demanda, resultando em um método cada vez mais acessível para a população.

A energia fotovoltaica se apresenta como uma das melhores formas para se obter uma geração de energia limpa, sustentável e ainda de maneira eficiente, uma vez que os sistemas de micro geração de energia podem ser instalados em telhados de residências, comércios e indústrias, o que diminuiria os impactos ambientais, não necessitando de novos espaços para a sua instalação.

Dentre seus principais benefícios está a possibilidade de sua interligação com o sistema de fornecimento de energia elétrica das companhias, dispensando o uso de banco de baterias, 
pois como o sistema fotovoltaico necessita da luz solar (o que não ocorre no período noturno), somente uma parte é consumida pela residência, sendo que o excedente é enviado para a rede pública, gerando um crédito com as concessionárias, crédito este que pode ser consumidor durante o período noturno, fazendo com que o usuário não necessite da energia gerada pela companhia de energia elétrica.

A relativa fragilidade consistente na eficiência de apenas $25 \%$ dos painéis solares não pode ser considerada como algo desabonador para este matriz energética, pois vários estudos estão em andamento no sentido de aprimorar o sistema de captação e absorção dos raios solares pelas placas fotovoltaicas.

Por fim, conclui-se que, se o sol é uma fonte de energia limpa e renovável, a geração de energia solar não está associada direta ou indiretamente à emissão de poluentes, o que evidencia os benefícios ambientais abordados nesta pesquisa em comparação com a matriz energética hidroelétrica, tendo como principal vantagem o fato de que não se utiliza de recursos que podem se extinguir com o tempo.

\section{REFERÊNCIAS}

ABSOLAR, Associação Brasileira de Energia Solar Fotovoltaica. Infográfico ABSOLAR. 2019. Disponível em: <http://www.absolar.org.br/infografico-absolar-.html>. Acesso em: 22 ago. 2019.

ANEEL. Energia no Brasil e no mundo. Disponível em: <http://www2.aneel.gov.br/arquivos/pdf/atlas_par1_cap2.pdf>. Acesso em: 02 jun. 2019.

ANEEL. ENERGIA SOLAR. Disponível em: <http://www.aneel.gov.br/aplicacoes/atlas/pdf/03-Energia_Solar(3).pdf>. Acesso em: 23 maio 2019.

ENERGÉTICA, Empresa de Pesquisa. Fontes de energia. Disponível em: <http://epe.gov.br/pt/abcdenergia/fontes-de-energia>. Acesso em: 02 jun. 2019.

ENERGÉTICA, Empresa de Pesquisa. MATriz ENERGÉTICA E ELÉTRICA. 2018. Disponível em: <http://epe.gov.br/pt/abcdenergia/matriz-energetica-e-eletrica〉. Acesso em: 23 ago. 2019.

IDEAL, Instituto. Beneficios e custos da energia solar - América do sol. 2018. Disponível em: <http://americadosol.org/beneficios-e-custos-da-energia-solar/>. Acesso em: 23 ago. 2019. 
LEMKE. Usinas hidrelétricas e seus impactos ambientais. 2018. Disponível em: $<$ https://engenharia-sustentavel.com/usinas-hidreletricas-e-seus-impactos-ambientais/>. Acesso em: 22 ago. 2019.

Ministério de Minas e energia. Energia. Disponível em: <http://www.mma.gov.br/estruturas/secex_consumo/_arquivos/7\%20-\%20mcs_energia.pdf>. Acesso em: 01 jun. 2019.

NASCIMENTO, Rodrigo Limp. ENERGIA SOLAR NO BRASIL: SITUAÇÃO E PERSPECTIVAS. Consultor Legislativo da Área XII. Recursos Minerais, Hídricos e Energéticos. Estudo Técnico (Câmara dos deputados). MARÇO/2017.

REIS, Leonardo. História da eletricidade. Disponível em: <https://www.mundociencia.com.br/fisica/historia-da-eletricidade/>. Acesso em: 01 jun. 2019.

REIS, Pedro. Vantagens e desvantagens da energia solar. Disponível em: $<$ https://www.portal-energia.com/vantagens-e-desvantagens-da-energia-solar/>. Acesso em: 03 jun. 2019.

RÜTHER, Ricardo. Edifícios solares fotovoltaicos. Florianópolis: Ufsc / Labsolar, 2004. 118 p. Disponível em: <https://fotovoltaica.ufsc.br/sistemas/livros/livro-edificios-solaresfotovoltaicos.pdf>. Acesso em: 02 jun. 2019.

SOUZA, Ronilson di. Os sistemas de energia solar fotovoltaica. Ribeirão Preto: Blue Sol, [2010]. 114 p. Disponível em: <https://programaintegradoronline.com.br/wpcontent/uploads/2016/03/Livro-Digital-de-Introdu\%C3\%A7\%C3\%A3o-aos-Sistemas-

Solares-novo.pdf >. Acesso em: 30 ago. 2019. 